\title{
Research centers in transition: patterns of convergence and diversity*
}

\author{
Laura Cruz-Castro ${ }^{* *}$, Luis Sanz-Menéndez and Catalina Martínez \\ CSIC Institute of Public Goods and Policies (IPP) \\ Consejo Superior de Investigaciones Científicas (CSIC), \\ C/ Albasanz 26-28, \\ E-28037 Madrid (Spain)
}

This is a pre-copy-editing, author-produced PDF of an article accepted for publication in The Journal of Technology Transfer following peer review. The definitive publisher-authenticated version [Research centers in transition: patterns of convergence and diversity, The Journal of Technology Transfer, 2012, 37, 18-42] is available online at http://link.springer.com/article/10.1007\%2Fs10961-010-9168-5\#page-1

\begin{abstract}
Governments continue to play a central role in the way research is conducted and organized by defining new models for research centers. How do existing research centers adapt to changes in their environment? Institutional theory suggests that organizations pursue efficiency and legitimacy by conforming to isomorphic pressures in their organizational field, which will eventually lead to a reduction of diversity in organizational practices and strategies. Resource-dependence theory assumes a more active agency and calls attention to the diverse strategic responses of organizations to institutional processes. Based on funding microdata and qualitative information at center level, this study undertakes to analyze changes in two populations of Spanish research centers (government laboratories and technology centers) in a time of evolving policy paradigms, emergence of new models for research centers, and increasing competition in the field of $\mathrm{R} \& \mathrm{D}$. We find that a large share of the existing government laboratories and technology centers have progressively conformed to a funding strategy based on diversifying sources and increasing competitive public funding, although both populations are still characterized by some degree of internal diversity regarding funding portfolios. Structural heterogeneity also remains as regards management practices such as research planning and agenda setting.
\end{abstract}

\section{Key words:}

Research centers, organizational change, funding strategies, research management, Spain.

\footnotetext{
* The authors acknowledge very useful comments and suggestions from Craig Boardman, Barry Bozeman, Denis Gray Arie Rip and JTT anonymous reviewers. We thank FEDIT, CSIC and CERCA for providing the raw data. Financial support is acknowledged from the Spanish Government through the Ministry of Science and Innovation (CSO-200803100/SOCI) and AECID (A/8159/07, A/018795/08).

*** Corresponding author: Email: Laura.Cruz@cchs.csic.es, Tel: (+34) 91602.2300, Fax: (+34) 91602.2971.
} 


\section{INTRODUCTION}

Despite statistics which show a shrinking role for the government sector in total expenditure on research and development $(\mathrm{R} \& \mathrm{D})^{1}$, governments are still key actors in research and innovation (Laredo and Mustar 2004). Governments shape the environment of research centers, both public and private, and through resource allocation, regulations and policy framing, they have the capability of conditioning what activities are considered as part of the legitimate research portfolio, how they should be implemented and even in what conditions -by what type of organizationsR\&D should be carried out.

There is evidence that governments and research funding agencies have promoted or directly created new types of research centers. For example, cooperative research centers or competence centers have been established in Australia, Austria, the Netherlands and other countries (OECD 2004), embedding a new model based on public-private partnerships, while research funding agencies (such as the US National Science Foundation) have promoted programs supporting the creation of engineering research centers (i.e. Feller, Ailes and Roessner 2002; Bozeman and Boardman 2004) or general university multidisciplinary research centers (i.e. Bozeman and Boardman 2003; Lin and Bozeman 2006) that usually involve a problem solving approach.

These policy developments are consistent with theoretical analysis claiming the emergence of a new mode of knowledge production (Gibbons et al. 1994; Nowotny, Scott and Gibbons 2001)2. Governments are demanding more cooperative, interdisciplinary and problem solving approaches to research; knowledge producers are increasingly expected not only to deliver high quality research under excellence parameters, but also to show a stronger focus on use, valorization and transfer, and these new demands create pressures to develop stronger cooperation between public and private actors. Governments are also demanding more social and economic relevance, that is, research that simultaneously addresses socially relevant problems and adopts theoretically pertinent

\footnotetext{
${ }^{1}$ The average government sector share of the total gross expenditure on research and development (GERD) in OECD countries has decreased from 18 percent in 1980, to 11 percent in 2007 (OECD 2009).

${ }^{2}$ We will not enter here into the debate about the novelty of this new mode (Weingart 1997, Pestre 2003),
} 
approaches (use-inspired basic research); what has been called "Pasteur's quadrant" (Stokes 1997) refers to research which represents excellence and relevance.

There is some empirical evidence, in Europe, that these developments are having an effect on the composition and nature of research centers; for example, the functions performed by traditional research centers are diversifying and among the recently created research centers there is a proliferation of private nonprofit legal forms (EUROLABS 2002); this trend has also been identified elsewhere (Rip 2002).

In Spain, despite the existence of a large sector of public research centers, governments have not directly promoted radical changes in the existing ones ${ }^{3}$, but instead have promoted the creation of a significant number of new research centers (hybrids) under a nonprofit legal form but publicly "supervised", with structures and strategies based on combining excellence and relevance; the features of these new centers constituting a new model.

The policies addressing these changes and those creating new research centers have already attracted some attention (Cruz-Castro and Sanz-Menéndez 2007), but our interest here lies in looking at the responses of previously existing research centers, public and nonprofit, to the changing environment and in analyzing how their organizational responses contribute to a reduction of heterogeneity among them and their conformity to this new model.

This paper analyses whether and how research centers from two diverse populations (government laboratories and technology centers) cope with the organizational changes needed to conform to the new model of research center. We analyze if, by adopting similar funding strategies and management practices, they are converging toward the position represented by that model, of which certain newly created hybrids are an example.

\footnotetext{
${ }^{3}$ Governments in other countries have promoted changes in research centers, some of them inspired by the New Public Management (Nedeva and Boden 2006; Boden, Cox and Nedeva 2006), that have ranged from privatization to implementation of new management practices; examples can be found in the United Kingdom (Boden, Nedeva and Barker 2004; Cohen, Duberley and McAuley 1999), New Zealand (Liyanage and Mitchell 1993), Canada (Smith 2000), France (Laredo 2001), United States (Jordan 2001) and other countries (Cox, Gummett and Barker eds. 2001). The general transformation of research centers, especially public ones, has also attracted attention from international policy think tanks (OECD 1989; OECD 2003) and academia (Van der Meulen and Rip 1994; Senker 2000; Jansen 2007).
} 
Our research questions are guided by some of the predictions of the literature dealing with organizational change and adaptation; more precisely, we evaluate the validity of certain hypotheses constructed on the grounds of institutional analysis and the extent to which isomorphic pressures in the organizational field exist and are accompanied by changes in existing research centers and promote convergence.

The paper is organized as follows. In the next section we present a brief description of the developments in research centers in Spain. We then present the framework for analysis, our research questions and hypotheses. In section four, we provide information about the concepts, data and methods used to address the questions. In section five, we examine the empirical evidence on the core dimensions selected for the comparison (funding strategies and management practices regarding research agenda setting) and we assess whether research centers follow similar or diverse patterns. We conclude by summarizing the results, noting some limitations of our analysis, indicating lines for further research and outlining some implications for theory and policy.

\section{RESEARCH CENTERS DEVELOPMENTS IN SPAIN}

Traditionally, the dominant models for non-company and non-university research centers in Spain have been those of government laboratories and technology centers. The former are mainly composed, on the one hand, of public research centers doing all kinds of fundamental and applied research under the umbrella of the Consejo Superior de Investigaciones Científicas (CSIC) and, on the other hand, of a number of public mission oriented research centers addressing specific knowledge areas, such as agriculture, energy, oceanography, aerospace, environment, health, etc. In turn, technology centers are private nonprofit research organizations providing applied $R \& D$ and technological services on demand to industry and enjoying some public support; these are similar to some European "Industrial Research Associations", "Collective Industrial Research" Centers or the US “Government Supported Privately Owned Research” Institutes. 
The subjects of our study are CSIC centers and technology centers, which jointly account for more than 10 per cent of the total Spanish GERD; they are referred to here as "government laboratories" and "technology centers" respectively.

As mentioned before, in Spain policy action has concentrated more on the creation of new research centers than in directly promoting changes in existing ones. In this context, a new generation of government-sponsored centers, both at the national and regional levels, began to be created in the late nineties and early 2000s with the status of private nonprofit foundations, and under a problem solving approach benefiting from significant involvement of knowledge users; the immediate driver of their development was the need to cope with bureaucratic rigidities and escape from public service models. The centers, referred as hybrids, explicitly aim to combine excellence and relevance, and compete with government laboratories and technology centers for funding and recognition ${ }^{4}$.

Thus, in response to the demands of both the national government and regional governments, or directly promoted by them, a new model of research center has emerged and is gaining growing support because it has acquired legitimacy ${ }^{5}$ and because of its compliance with the normative elements of a new (increasingly dominant) policy model that emphasizes autonomy, accountability, excellence, relevance, and economically and socially oriented research. We use the label "hybrid" research centers because they combine elements from existing models, they are the result of public

\footnotetext{
${ }^{4}$ The National Research Center on Cancer (CNIO) is probably, if not the first, the canonical exemplar because of impact and size; it was created at the initiative of the Ministry of Health in 1998. The CNIO was established following the model of a publically controlled but private nonprofit foundation (Barbacid 2008); another is the National Cardiovascular Research Center (CNIC). Additional hybrid centers have been created with the involvement of regional governments (the most active has been the Catalan Regional Government), universities and other public research organizations (including hospitals), in different fields of research; examples include, in the area of biology and biomedical research: the Center for Genomic Regulation (CRG) created in 2000, the Center for Regenerative Medicine in Barcelona (CMRB) created in 2004 and the Biomedical Research Institute (IRB) created in 2005; or in the area of engineering and physical sciences, the Institute of Chemical Research in Catalonia (ICIQ) created in 2000 and the Catalan Center for Telecommunication Technologies (CTTC) created in 2001. The regional governments monitoring these new centers usually establish long term funding and management contracts (Contratos Programa) defining measurable objectives, supplying resources via block grants amounting to no more than 50 percent of total expenditures, and fixing target objectives for funding from competitive and private sources.

5 They also appear to be more efficient in terms of competition for funding and recognition; despite their recent creation and small number, the new hybrid research centers have been very successful. For example, in the first call for proposals launched by the European Research Council (ERC), evaluated exclusively on the basis of quality and excellence at the European level, the hybrids have obtained 13 out of the 25 Starting Grants and 6 out of the 13 Advanced Grants awarded to all Spanish institutions, ahead of other government laboratories and universities (information as of 24 April 2009).
} 
initiatives and they are under public control, but at the same time they usually have a private nonprofit legal status.

Based on empirical data from a few of them and the analysis of their political design, we found that the hybrid model has, by design ${ }^{6}$, more diversified funding (between public block grant, competitive public and market funding) and follows a more "authoritative" management and agenda setting model than traditional research centers. Table 1 summarizes some of the general features of the new hybrid centers, and of the two populations of previously existing research centers analyzed in this paper, government laboratories and technology centers.

Table 1 ABOUT HERE

Some features of the new hybrids which depart from those characterizing pre-existing research centers, are their funding structures, their distinctive professional career tracks, the involvement of knowledge users, public-private partnership, the specific process for defining research objectives and agendas and the ability of management to adopt long term problem oriented approaches. Among the key features that allow these new centers to orient their research strategically in search of excellence and relevance are increased management capabilities for organizational agenda setting and the diversification of funding sources ${ }^{7}$. In the statutes or constitutional arrangements of the new hybrids there are always objectives of balanced funding, limits to the share of block grants,

\footnotetext{
${ }^{6}$ In a preliminary analysis of 7 hybrids (see footnote 3 above) we found that in all cases the creation of the new center started with the selection of the Director, the development of a research project and the establishment of a multiannual "management contract" with the principal (promoter) fixing funding mechanisms and scientific objectives.

${ }^{7}$ For the purpose of providing an empirical snapshot of the new hybrid centers we have used a group of 6 hybrid centers [one created under the national government (CNIO) and 5 under the Catalan regional government (CRG, CMRB, IRB, ICIQ, CTTC)] as a reference. For 2008 on average 56 percent $(\sigma=1)$ of the funding for these six centers was from non-competitive public sources, 29 percent $(\sigma=5)$ from competitive public sources and 15 percent $(\sigma=5)$ from private market sources.
} 
targets for getting competitive public funding and even commitments and institutional devices for defining high private contributions ${ }^{8}$.

In the Spanish context public R\&D centers are structured so that direct government funding is non discretionary, in other words, it is earmarked to be primarily spent on permanent researchers' salaries and infrastructure maintenance. The increase in competitive public funding increases the autonomy of these centers by increasing the maneuverability or discretion of the management of government centers and therefore the strategic capabilities of centers.

New hybrids also face fewer constraints (for example, regarding contracting and human resource management rules) because promoters (in national and regional governments) of these centers have sought to distance them from the regulations of the traditional public administration service to make them more efficient and flexible to participate and succeed in the increasingly competitive research environment.

It is our contention that the policy changes promoting a new model of research center are producing a transformation in the organizational field; our interest lies in describing how some of the existing research centers (government laboratories and technology centers) have evolved in this context, and in testing some of the predictions emerging from institutional theory, which provides explanatory mechanisms.

\section{ANALYTICAL FRAMEWORK}

In previous research (Cruz-Castro and Sanz-Menéndez 2007) we have described the way in which different institutional logics evolve in the research and development organizational field and how new models for research activities emerge and consolidate. We argued that government intervention played a central role in initiating the structural transformations of research

\footnotetext{
${ }^{8}$ For example, the National Cardiovascular Research Center (CNIC) which has emerged as a model of public-private partnership, has a strong commitment from private industry (13 companies) to contribute 180 million euros over a 10year period, to cover 32 percent of CNIC's expenditure budget (Sanz and Fuster 2008).
} 
organizations, sometimes by exerting pressure through their control of funding, sometimes by exercising their power to regulate (Frumkim and Galaskiewicz 2004).

In this section we will first present the conceptual framework (what has been called publicness) to account for the blurring boundaries between public and private research centers; and then we will look at the causal mechanism (isomorphic pressures) that could account for changes and explain convergence.

Public administration literature has provided some comparative analyses of private and public institutions (i.e. Perry and Rainey 1988; Rainey and Bozeman 2000), pointing to the emergence of hybrid forms and blurred boundaries between them. Strong claims have been made, such as that "all organizations are public", whether they are governmental, business, or nonprofit (since they all are, to some extent, subject to public authority). Bozeman and other authors have applied this concept to analyze diversity among research centers (Bozeman 1987; Bozeman and Crow 1990; Crow, Emmert and Jacobson 1990; Crow and Bozeman 1998); they developed an empirical taxonomy to classify research laboratories under two dimensions: their degree of "publicness" and the economic nature of the outputs, particularly their market or public characteristics. This taxonomy (Figure 1) reveals that boundaries between public and private organizations are more permeable than before. "Publicness" is a multidimensional concept that points to the constant influence of government authority (Bozeman 1987); the term was introduced to signal that political authority and control of resources are exerted over all types of organizations, though to highly varying degrees in regards to the role of government in setting or shaping the agendas of $R \& D$ centers, the amount and share of resources that come from government (via contracts, grants, subsidies, or other vehicles) and government control of the structure and design of the centers. Needless to say, "publicness" does not equate to government ownership. In fact, these authors claim that public technology laboratories have a number of distinctive common characteristics regarding funding and research agendas, and that these characteristics hold true regardless of ownership differences. 
In this paper, comparisons are drawn between two types of research centers. On the one hand, government laboratories that would fall in the lower right area of the taxonomy, and, on the other hand, technology centers falling in the upper left area; however, though this taxonomy allows us to classify the centers and think of their position in the field, the conceptualization itself does not address organizational change.

We are interested in testing whether there has been any "change" in the existing centers, in terms of their funding strategies and management practices, toward the new model. The institutionalist approach ${ }^{9}$ provides some key elements and causal mechanisms to address the issue of change and the adaptation of research centers to market forces and a changing political environment. Institutional pressures do not affect all organizations in the same way; nonprofit and government establishments are more vulnerable to institutional or legitimizing influences (Frumkin and Galaskiewicz 2004). The link between conforming to the expectations of stakeholders and legitimacy is a key element to understand isomorphism (or convergence) in certain organizational fields, especially those which, like R\&D, are subject to strong public policy influence and support.

Thus well established and stable research centers are subjects of interest for testing some basic predictions of institutional theory regarding isomorphic developments as a way of compliance (Meyer and Rowan 1977). Both rational adaptation theorists (Scott 1995) and institutional isomorphism perspectives (DiMaggio and Powell 1983) argue that over time organizations in the same organizational field ${ }^{10}$ will have a tendency to adopt similar structures and practices (those appearing to be efficient and legitimate). DiMaggio and Powell pointed to three forces that lead

\footnotetext{
${ }^{9}$ For a recent review, see for example Scott (2008) or Organizational institutionalism, edited by Greenwood, Oliver, Suddaby and Sahlin (2008).

${ }^{10}$ DiMaggio and Powell (1983) defined "organizational fields" as "those organizations that, in the aggregate, constitute a recognized area of institutional life: key suppliers, resource and product consumers, regulatory agencies and other organizations that produce similar services or products" (1983: 148-149). They also highlighted the process of structuration of the field through interactions and connections between members, leading to recognition of their mutual involvement in a common enterprise (1983: 148).
} 
organizations in the same field to become isomorphic (more similar in some aspects): regulative, mimetic and normative pressures. Regulative pressures arise from political influence, but can also derive from resource dependence and demands or expectations from the policy side that organizations adopt specific practices, for example, in order to be eligible for public subsidies or grants. Mimetic pressures result mainly from conditions of uncertainty that make organizations imitate those which are seen as successful. Normative pressures are related to what is considered the appropriate course of action, and are often related to professional values and social norms and expectations.

The major empirical prediction made by this approach is that, over time, organizations within the same field will become more similar; however the emphasis is on incremental rather than on radical change. Isomorphism or convergence can be detected by the reduction of diversity across organizations in some central dimension or by an increasing degree of similarity.

The majority of empirical studies on isomorphism have concentrated on the mechanisms through which it happens, i.e. the three types of pressures outlined by DiMaggio and Powell (Boxenbahum and Jonsson 2008; Mizruchi and Fein 1999), and very few have investigated isomorphism (or its absence) as an outcome (e.g. Meyer, Scott and Strange 1987). Interestingly, some of the few exceptions focusing on isomorphism as an outcome have found evidence against increasing homogeneity (Kraatz and Zajac 1996). Other authors have questioned the argument that once subjected to institutional pressures, organizations tend to conform or disappear. Perspectives that take organizations more as active agents than as pure subjects, consider that organizations can respond differently and strategically to institutional pressures (Scott 2008: 431). For example, Oliver (1991) suggested, combining institutional with resource dependent elements, that conformity to the institutional environment is neither inevitable not invariably instrumental for organizations (Oliver 1991). She found that the variety of responses included compliance, compromise, avoidance, defiance, and manipulation. However, she acknowledged that when an organization anticipates that conformity will improve social or economic fitness (in other words, 
legitimacy and efficiency) compliance will be the most probable response to institutional pressures; but decoupling is also a pattern of response that could be identified (Heimer 1999; Ruef and Scott 1998; George et al. 2006).

Institutional theory and its empirical developments have placed their main focus on private organizations. ${ }^{11}$ Previous empirical studies on isomorphism have been ambiguous about the relevant dimension and level of analysis where similarity should or should not happen in order to confirm the institutional isomorphism. ${ }^{12}$

This discussion leads to our main research question about whether or not isomorphic developments have taken place in government laboratories and technology centers. Institutional theory would predict a reduction in the heterogeneity or diversity of organizational practices and strategies. DiMaggio and Powell conceived isomorphism both as a state and a process. Here we acknowledge this dual conceptualization. We undertake a research center-level analysis of changes in certain characteristics of two populations of fairly stable traditional research centers over time and analyze the extent to which they tend to resemble the new type of research centers

For the purpose of the comparison and to test the changes we have selected two related dimensions which are fundamental to understanding the centers' capacity to strategically orient their research activities: i) funding strategies; and ii) research agenda and management practices. Public Administration literature has pointed to funding (i.e. Bozeman 1987; Perry and Rainey 1988) as a relevant element in the transformation of the ownership of public or private nonprofit centers. The diverse ability of government laboratories to cope with funding crises through seeking external funds has also been analyzed (Schimank and Struke 1994; Sanz-Menéndez and CruzCastro 2003). Additionally, resource dependence theory suggests that public and private centers will reduce their dependence on a single source and diversify their sources (Scott 1987). Now we will look at whether the two types of centers analyzed in our study converge and adopt a pattern

\footnotetext{
${ }^{11}$ There are exceptions such as Ashworth et al. (2009).

12 Scholars have identified several organizational attributes that are subject to isomorphism, and whereas initial concerns were with structures and practices, more recently, strategies have also become a focus of analysis (Fligstein 1991; Haveman 1993; Deephouse 1996).
} 
similar to the hybrid centers, reducing dependence on their main traditional funding sources (non competitive public funds for government laboratories and market funds for technology centers) and relying more on competitive public funding calls, where excellence and socio-economic relevance are the main criteria of selection.

Hypothesis 1. Centers within the organizational field ${ }^{13}$ will adopt similar funding strategies: actively searching for competitive public funding and reducing the share of funding coming from their traditionally predominant source.

As regards the second dimension -research agenda setting and management practices-, the literature on new public management and case studies of the changes in research centers has highlighted the relevance of this feature. We focus our analysis on the planning dimension and, more specifically, on the degree of authority of the management of the centers with respect to research planning and agenda setting. For the analysis of this dimension we make use of the categories outlined by Liyanage and Mitchell (1993). They identify three different decision-making models emerging in Australian research centers: an "executive control model" with a strong line of decision filtration, command and control; a "consensus model" where decisions are made in consultation with several organizational layers of managers and key partners; and an "authoritative model", based on direct control of the director over decision-making, counterbalanced by advisory committees, the latter would fit with the practices of the new hybrids.

Hypothesis 2. Centers within the field will change in the direction of having stronger organizational research agendas and a more "authoritative" style of strategic management, either based on scientific leadership or managerial authority.

\section{DATA AND METHODS}

\footnotetext{
${ }^{13}$ We adopt the definition of organizational field given in footnote 10 but the hypotheses are tested on two populations of centers which are knowledge producers.
} 
We have selected two different sets of research centers which are in the same organizational field, despite their own specificities and trajectories. First, a population of research centers doing applied R\&D and offering technological services to industry: the technology centers. Most of them have evolved from and still have significant features of "industrial research associations" created to provide technological solutions to firms (usually small and medium enterprises -SMEs-). They have a private nonprofit status, either under the legal form of "foundation" or "association", but they tend to have significant relationships with the regional governments in which their facilities are located. There is a private, self-organized association of these technology centers: FEDIT (Spanish Federation of Technology and Innovation Entities). Overall, in 2007 the 67 affiliated centers had, in aggregate, more than 6,300 employees and an income of 520 million Euros and represented 4 percent of the Spanish expenditure on $R \& D^{14}$.

Second, a set of government laboratories under the umbrella of the CSIC, the largest government research performing institution in Spain, where research activities are organized through a total of 124 research centers, all over the country in all fields of research. The total budget managed by CSIC was around 800 million Euros (representing 6 percent of the Spanish expenditure on R\&D in 2007). CSIC employs more than 12,000 people in research.

The complexity of addressing change in organizations and monitoring potential isomorphic developments in terms of funding strategies and management practices requires the use of diverse data and methods. In this paper, we have combined quantitative and qualitative data in the following way: First, we collected quantitative data on sources of funding for both populations of centers, based on the consideration that a funding strategy is characterized by the portfolio of financial resources that the center gets from different sources, measured as shares of total income. On the one hand, for technology centers, we combined the data which FEDIT collects with information from other sources to create an original database for this study, with data for the 2002-

\footnotetext{
${ }^{14}$ The total income and number of employees of the 62 technology centers affiliated to FEDIT in 2007 that had also been members in 2006 increased 17 percent and 10 percent respectively between 2006 and 2007 (source: FEDIT database).
} 
2007 period. Excluding centers for which we did not have complete data for the whole period, we built a database with full information on 54 technology centers, members of FEDIT ${ }^{15}$ On the other hand, CSIC regularly collects accounting data from all its centers, which is published in the annual reports of the institution and the individual institutes. Based on the data available ${ }^{16}$ we constructed an original database with information on aggregated levels of expenditure (broken down by sources of funding: "internal" funds to cover current and capital expenditures -and allocated by direct transfers by the CSIC headquarters- and "external" income -from all types of external sources from public competitive calls to contracts with industry- $)^{17}$ for each center, between 2002 and 2007. We excluded a number of centers from the analysis due to lack of data for any of the relevant dimensions considered. ${ }^{18}$ This left us with 81 CSIC institutes for which we have a full data set on income by different categories for the 2002-2007 period (representing an average of 80 percent of total expenditures and 86 percent of the staff of all CSIC institutes).

In summary, we analyze 135 research centers (54 technology centers and 81 government laboratories) using 3 funding variables (with a 6 year observation period, from 2002 to 2007):

- Public non competitive funding share, which represents the share of the total annual budget of the research centers resulting from "direct public subsidies".

- Public competitive funding share, which represents the share of the total annual budget of the research centers that results from "indirect public sources", mainly through competitive funding.

- Market funding share, which represents the share of the total annual budget of the research centers that comes from contracts and services.

\footnotetext{
${ }^{15}$ FEDIT had 61 affiliated centers in 2002 and 67 in 2007, but not all of the initial 61 centers remained until 2007 and some new centers joined the federation after 2002.

${ }^{16}$ For the calculation of income by funding sources, CSIC institutes were considered as independent entities. CSIC central headquarters expenditures (68 million euros in 2007, 8.95 percent of the total expenditure budget) were neither taken into account, nor proportionally attributed to analyzed institutes.

${ }^{17}$ To break down external funds into those coming from public competitive calls and those coming from market sources (such as R\&D contracts with industry) we made use of additional data available at the center level on external income broken down into fourteen different categories, four of them are related to public competitive calls (national general, national health-related, regional and European).

${ }^{18}$ We have excluded social sciences and humanities CSIC centers (16), representing 10 percent of CSIC research staff and budget. The reason is twofold. Firstly, there are no technology centers operating in those areas. Secondly, none of the new hybrid centers that we are taking as the reference model belong to those fields. We therefore believe their exclusion does not bias the analysis and facilitates the comparison with the technology centers.
} 
The increasing homogeneity (or the reduction of diversity) of research centers over time together with a change in the distribution of funding sources to resemble the hybrid centers would be an outcome consistent with Hypothesis 1. We first tested if the two populations subject to our analysis were significantly different in funding strategies; and then analyzed changes in funding sources over time. The identification of a large group of government laboratories and technology centers with funding strategies evolving in the directions indicated in Hypothesis 1 would provide support to some isomorphic developments.

Secondly and complementarily, we conducted a series of semi-structured qualitative interviews: a group of interviews in five government laboratories ${ }^{19}$, and a group of interviews with top managers in seven technology centers ${ }^{20}$. The interview protocol was the same for all interviews and questions were addressed to the interviewees in order to identify stability or change over the last decade as regards the research agenda setting process and the role of management.

In the interviews, two key concepts were discussed with the interviewees. They were defined and explained to all respondents in the same way. They were then asked to explain whether and how these categories applied to their centers. First, we referred to the development of "scientific or managerial leadership" within the centers. We operationalized this concept with two dimensions: a) the existence in the organization of a research director or a management/scientific board carrying out the role of defining the research lines of the centre; b) the existence of rules, either formal or informal, that preclude individual researchers or research groups from selecting research lines and/or writing grant proposals without prior consultation with the scientific or managerial hierarchy within the organization. Our decision rule was to consider an affirmative response to at least one of the dimensions to be an indicator of this development.

\footnotetext{
${ }^{19}$ Three of these research centers belong to the area of physics, one to biology and one to chemistry. We conducted 13 interviews, 4 with department directors, 5 with directors of research groups, and 4 with other tenured researchers.

${ }^{20}$ We identified two basic types of technology centers. On the one hand, those technology centers which were strongly tied or oriented to an industrial sector in particular, and, on the other hand, those with a broader technological scope. We covered this variance when selecting the interviewees.
} 
Secondly, we discussed the existence of "organizational research agendas" understood as top level program or project planning. We explicitly highlighted this as being different from the bottom up aggregation of individual or research groups' projects in the case of government laboratories, or the bottom up aggregation of market demands coming from local firms in the case of technology centers. We operationalized the concept with three dimensions: a) the existence of strategic research planning, that is, the implementation within the organization of formal, systematic and ruled procedures to identify research strengths, competitive opportunities, select priorities and allocate resources within the different departments/groups accordingly in a medium to long-term basis; b) the use of medium to long term research time frames. We divided research planning time frames between project basis (usually short term, up to 2 years), and program basis (usually multiannual, up to five years); c) the existence of formal performance evaluation mechanisms beyond the individual level. Our decision rule was to consider an affirmative response to at least two of the dimensions an indicator of this development.

\section{RESULTS}

\subsection{Funding strategies}

Using information on the portfolio of funding sources by center, the objective of this subsection is twofold. First, to map the position of government laboratories and technology centers regarding non competitive public, competitive public and market funding sources at the beginning and at the end of the time period analyzed. Second, to determine to what extent technology centers and government laboratories are converging or not (or moving into the direction of more diversified strategies) towards the new model represented by the hybrids, and how such evolution is being affected by the internal heterogeneity of both populations. Hypothesis 1 will be supported if we find that centers have diminished their dependence on their population's predominant funding sources and have increased competitive public funds.

\subsubsection{Funding sources in different populations of $R \& D$ centers}


There are significant differences between government laboratories and technology centers as regards the distribution of income by funding source. Direct public support is the most important source for government laboratories, providing around 71 percent of their resources on average, whereas market sources take the lead for technology centers, concentrating on average 58 percent of their income. Thus, non-competitive public funds are the traditional funding source for government laboratories, whereas for technology centers it is market funds. Differences are not so marked, but also significant, for the share of competitive public funding (from European Union, national and regional sources), which equals around 24 percent for government laboratories and 32 percent for technology centers (see Table A1 in the Annex). ${ }^{21}$

As regards evolution over time and diversity within populations, Figure 2 below represents the frequency distribution of $R \& D$ centers (in percentages by population) with respect to bi-annual average income shares for the three types of funding sources at the beginning (average 2002-2003) and at the end of the six-year period analyzed (average 2006-2007). ${ }^{22}$

\section{Figure 2 ABOUT HERE}

At first sight, both populations seem to have slightly moved in the directions predicted by Hypothesis 1, with non competitive public and market funding average shares decreasing two percentage points for both government laboratories and technology centers in the analyzed period, and shares of income from competitive public funds increasing two percentage points for government laboratories and six for technology centers. In addition, dispersion around the mean not only has decreased over the years for all three types of funding shares in both populations, but the standard deviation has decreased relatively more than the mean for traditional funding sources,

\footnotetext{
${ }^{21}$ T-tests on the difference of the means for shares of income by funding source indicate that there are significant differences between both populations for all three sources every year, except for competitive public funds in 2004 (see Table A1 in the Annex).

${ }^{22}$ We have used two year averages to reduce short term fluctuations.
} 
indicating a reduction of variability within each population which would be consistent with convergence towards the diversification of funding sources predicted by Hypothesis 1 .

However, although some centers seem to have indeed moved in the directions predicted by Hypothesis 1, driving their population means accordingly, most changes are not statistically significant when analyzed at the research center level for each population. ${ }^{23}$ A more detailed analysis is therefore required and undertaken in the next section to test the validity of Hypothesis 1.

\subsubsection{Funding sources at individual $R \& D$ centers within different populations}

The objective of this subsection is to assess how many individual R\&D centers within each population have conformed to the expected changes and how many have not. With that aim, we conduct an exploratory clustering analysis for each population based on the differences in bi-annual average funding shares from each source between 2002-2003 and 2006-2007 and identify three distinct patterns of change for each share of average bi-annual income within each population (See Annex Table A2). ${ }^{24}$ Based on this, we build four subgroups composed of centers which have experienced the following similar changes in funding shares during the period, and identify each of them with a different "funding strategy":

- Strategy 1 , less traditional, more public competitive public funding

- Strategy 2, less traditional, less competitive public funding

- Strategy 3, more traditional, more competitive public funding

- Strategy 4, more traditional, less competitive public funding

\footnotetext{
${ }^{23}$ Paired samples T-Tests for the difference of average bi-annual funding shares at the beginning and at the end of the period were only found significant for the decrease in non competitive public funding $(\mathrm{t}=2.236, \mathrm{p}=0.03)$ and the increase in competitive public funding income shares $(\mathrm{t}=-3.062, \mathrm{p}=0.003)$ in technology centers. Thus, changes over time were not statistically significant for funding shares from market sources at technology centers or for any of the three funding shares at government laboratories.

${ }^{24}$ Annex Table A2 sets out the results of the six cluster analyses of funding changes undertaken, one for each population and type of funding share. We consider that a technology centers or government laboratory included in a specific cluster by the K-means clustering algorithm has adopted the change indicated by the value of the "final cluster center". For example, we consider that all the 33 technology centers included in Cluster 1 of non competitive public funding changes have experienced a low decrease in non competitive public funding. Two possible changes are accounted for in view of the results, decreases (negative final cluster center) and increases (positive final cluster center), of two different levels each (low: less than one percentage point change; and high: more than one percentage point change), although to facilitate the presentation of results, both low and high changes are added together later in Figure 3.
} 
This analysis shows that 72 percent of the technology centers and 64 percent of the government laboratories have opted for Strategy 1 moving in the directions predicted by Hypothesis 1, reducing their share of income coming from traditional sources (non competitive public funding for government laboratories and market funds for technology centers) and increasing their share of income from competitive public funds (Figure 3). The few research centers which have adopted Strategy 2, characterized by less traditional and less competitive public funds (11 percent of the technology centers and 2.5 percent of the government laboratories), would have also reduced distances with the new model of research center by decreasing their dependence on traditional funding sources, but through other means. Government laboratories would have increased their market funding share, and technology centers their non competitive public funding share. On the other hand, Strategy 3 (more traditional, more c competitive public funding) would be adopted by research centers that have reinforced dependence on their population's traditional funding sources, that is, centers that do not move towards convergence, which are equally represented in both populations ( 7.4 percent). Strategy 4 (more traditional, less competitive public funding) would in turn be associated with those R\&D centers which are least prone to the changes predicted by Hypothesis 1, a proportion that is higher amongst government laboratories (26 percent) than amongst technology centers (9 percent) indicating a higher degree of inertia in the government R\&D sector.

Figure 3 ABOUT HERE

\subsection{Research planning and agenda setting}

The management practices of research organizations have multiple and complex dimensions. We have chosen to focus on the authority of the management of the centers with regard to research planning and agenda setting and its time frame. According to Hypothesis 2, centers within the field 
will become similar in the sense of developing stronger scientific or managerial leadership and having stronger organizational research agendas, a pattern that we identified in the hybrid type.

The management model of technology centers has been traditionally determined by their dominant nature as former "industrial associations" and by the fact that their core mission was to provide their affiliated firms with technologies and services on demand. Accordingly, the management boards of technology centers have always had a significant level of representation from the industrial and business sector, and research priorities, very much oriented to industrial applications, were drawn either from interests of the sectors or following demands of the firms.

All technology center directors interviewed identified a top level organizational layer with the role of selecting research lines. Moreover, the majority of the directors reported that decisions about the orientation of the technology centers were traditionally taken by themselves in response to demands from the boards, and filtered down to the working units which were not autonomous to select research or development lines by themselves. Long term research planning has not traditionally been the norm. This was the standard approach until the mid nineties, as verified in interviews with center directors, who reported that before then it was difficult to identify an organizational agenda other than that derived from the aggregation of market demands, mostly coming from local firms and associated industries. This is coherent with the expectation that organizations with low levels of publicness generally plan short term and are subject to rapid, market induced changes (Bozeman, 1987: 136).

Government laboratories are engaged in research that is mainly directed to the public domain, which is coherent with the fact that, historically, they have received a substantial part of their budget from the central government in the form of institutional block grant funding to cover current expenditure, investments in new facilities, and the salaries of permanent staff, who are civil servants. Traditionally, government laboratories have been organized in research departments and research groups, and headed by a laboratory director, appointed by the president of the institution, but previously elected by the laboratory's assembly among the permanent research staff. Despite 
being a formally hierarchical organization under ministerial control, neither the government nor the Presidency has ever used their authority to set up scientific agendas through institute directors, because, unlike mission-oriented public laboratories, government laboratories under study have no stable specific research mission other than the advancement of knowledge.

In a similar way to researchers at universities, historically, research groups and individual researchers at government laboratories have enjoyed high degrees of autonomy for pursuing particular research lines and implementing their projects independently of any scientific hierarchical approval or supervision, provided they managed to succeed in getting grants. Government laboratories, until very recently, did not develop strategic research planning, and directors were perceived more as administrators than as scientific leaders. One of the permanent researchers interviewed stated, for example:

"in general, directors did not have either power or very often the willingness to be authoritative about what research would be conducted in the departments; it has always been part of the organizational culture of the government laboratories that management would not interfere in the scientific agenda of the researchers" ... "you (as a researcher) would write your applications for grants and only before submitting them to a funding agency would you need the signature of acknowledgement of the President of the Board (but not that of the director of your center), but this was a mere formality" (Government laboratory permanent researcher).

And a department director added:

"the director (of the laboratory) provides the signature for all kinds of bureaucratic decisions you can imagine, but the work of the researchers in their laboratories seems to take place quite independently of all that,... for example, if a group wants to hire a research assistant or engage in a particular project, the important thing is to have the financial resources; then, the approval by the director would be almost routine". (Government laboratory department Director).

In comparison with researchers at technology centers, researchers at government laboratories centers have in general been less dependent on the scientific and technological physical infrastructure, except for the medium and large sized equipment needed in some areas, and this has provided them with further autonomy vis à vis the management of their centers.

As we have seen, technology centers have confronted challenges and changes in recent years, both due to the sophistication of private demand and because of the emergence of new "mission" 
demands coming from the public sector, mostly from regional governments (Moso and Olazaran 2002; Sanz-Menendez and Cruz-Castro 2005). Overall, changes in their funding strategies have increased their levels of "publicness" and this move has been accompanied by some transformation in their management practices. In general, it becomes clear from the annual reports of the centers that their governing boards have been enlarged to include more regional representatives with broader interests in the socioeconomic relevance of the work of the centers for the region. When we discussed the existence of "organizational research agendas", technology center directors identified two different timeframes and two levels of decision making. While most directors reported that they have kept the short-term projects addressing firms' needs through contract research, some of them have started to plan strategically to include medium-term generic projects and training of researchers and are doing so through systematic procedures, in most of the cases through strategic plans, which sometimes include foresight exercises. As one of the directors put it:

"we have moved from working almost exclusively on demand to anticipating what our competitive advantage in the market of industrial development could be, knowing that we have collaborators and competitors...firms demand solutions for today's problems, but now we also look for information on how to anticipate their needs". (Technology Center Director).

Decisions about this second type of research line, which involves multiannual planning, are mostly taken at the top level of management, and following top down consultation processes with several organizational layers of heads of departments and working units ${ }^{25}$. The relationship between autonomy and performance, as well as the relevance of the program directors or department directors' level in the agenda setting process, as well as the idea that relative autonomy was connected with performance was also emphasized in the interviews in technology centers:

"researchers are quite free to try particular research avenues, however, they know that at some point they will be evaluated and will have to show that their research is profitable; no success means little professional advancement in the center, so yes, they can be autonomous but they are also accountable"... "authority is distributed mainly among the board and the program directors... they (the program directors) are the key intermediate decision layer" (Technology Center Director).

\footnotetext{
${ }^{25}$ Two of the center directors highlighted that although this approach involves greater market risks, it can also yield potentially higher returns in case of success because it implies the future selling of generic technologies to broader markets.
} 
Despite changes in their funding strategies, we have not yet found such a degree of managerial change in government laboratories in general. Overall, government laboratories maintain a bottomup management style with emphasis on individual researchers who enjoy high degrees of autonomy. As a consequence, very few respondents claimed the emerging existence of organizational research agendas. As discussed in the interviews with researchers and group directors, research agenda setting continues in the present to be the result of the aggregation of individual and research group research agendas, rather than being based on highly structured research programs at the organizational level. Moreover, we have not identified a strategic planning function in the organizational tree of government laboratories, and when asked to identify a top level in their organizations with the role of defining research lines, the great majority of respondents (of a total of 13) said there was not such a level. There is no clear evidence that government laboratories are moving towards more "authoritative" planning processes with strong organizational research agendas, similar to those of the new model of hybrid centers which are increasingly central in the organizational field. Moderate to high levels of publicness seem to be a necessary but not sufficient condition for long-run planning processes and the definition of appropriate tools.

\section{Table 3 ABOUT HERE}

It has only been very recently, in 2006, that the process of transformation of these government laboratories (CSIC) into an agency has begun to introduce strategic management into the practices of these centers, which now have to elaborate a four year strategic plan, subjec to external peerreview, and that is the basis of the program-contract with the ministry. The first strategic plans were elaborated for the period 2006-2009, but it is too early to assess their impact. No evaluation has been conducted yet.

In sum, support for Hypothesis 2 is not conclusive. On the one hand, some technology centers seem to increasingly conform to the new model of long-term strategic organizational research 
planning, but a substantial degree of heterogeneity remains prevalent among them. On the other hand, the majority of government laboratories are still characterized by agendas that are built bottom up with emphasis on individual researchers, although some efforts have been recently made to elaborate strategic plans, and there are cases of centers with stronger scientific leadership at the directorship level than the average government laboratories, resembling some features of the new centers of reference. As one interviewee pointed out:

"In a few centers you find directors, we could call them star scientists, who are able to set the agenda, in cooperation with their peers, because they attract a lot of human and financial resources but they are exceptions" (Government Laboratory Director).

Evidence for Hypothesis 2 suggests that organizations are still characterized by structural heterogeneity and that inertia is quite significant, especially in government laboratories.

\section{CONCLUSIONS}

This article has explored isomorphic developments and change in two populations of fairly stable Spanish research centers: Government laboratories and technology centers. Our analysis has addressed one key issue in organizational change: the occurrence of convergence among organizations within the field across two different organizational characteristics: funding and research planning and agenda setting. We have shown that different types of research centers have confronted transformations in their environments and have developed diverse processes of adaptation and change. This has gone hand in hand with the consolidation of a new type of hybrid research center (that favors excellence, cooperation, knowledge and technology transfer and relevant problem-oriented research), which conforms with the new model of R\&D center promoted at the policy level, and has increased the level of competition in the research field. The results of our analysis are partially consistent with our first hypothesis, but diversity remains across and within the two populations analyzed regarding changes in funding strategies. In addition, the extent 
to which evolving funding strategies have been accompanied by isomorphism in managerial and research planning practices is rather low.

The case of the technology centers shows the movement of formally "private" but non-profit research centers into arenas of competition for public funds with other actors. Technology centers have changed the nature of their "publicness" through changes in their funding strategy, (getting less market and more competitive public funding over time) to increase their generic $R \& D$ capabilities in addition to meeting the demands of the market, which continues to provide the most stable component of their funding strategy. This is consistent with the interviews with technology center directors, where some of them reported having changed some of their traditional corporate management features and adopted agenda setting processes that depart from the short-term, market driven planning to more strategic long-term approaches, albeit with differences in the level of centralization of the decision making processes about the agenda.

Government laboratories show more stability in the distribution of funding sources in the period analyzed than technology centers, since one third of them are increasing funding from traditional sources (non competitive public funding) compared to only 17 percent of technology centers (for which the traditional funding source is the market). Government laboratories' degree of conformity towards the emerging model of a more centralized scientific leadership with executive powers over agenda setting and strategic research planning is also rather low. One likely explanation might be that structural changes are slower in public organizations in the absence of legal, coercive transformations, particularly when these changes involve centralizing executive power at the directorship level in organizations traditionally controlled by professional communities (researchers).

The differences we found in our two populations of centers also show that institutional pressures do not affect all organizations equally. When the perceived gains in terms of efficiency or economic gain are high, private nonprofit research centers, who, after all have patrons and funders to which they are accountable, seem to conform more both in funding strategies and structural 
changes than government laboratories. Both government laboratories and technology centers have perceived efficiency and legitimacy gains from conforming to the model of center financially based on a diversity of funding sources with increasing reliance on competitive public funds, and therefore, more autonomous, and more oriented to knowledge and technology transfer. But some of them have responded more actively or more rapidly to the model.

Our hypotheses predicted a reduction of diversity and a convergence among research centers towards a new model of research center (of which hybrid centers are an example) but, looking at funding strategies and management practices together, our analysis has only partly confirmed that trend. There are various ways of interpreting these findings and improving the analytical framework. One is to question the basic assumption that the institutional environment will produce a single type of response, and convergence. Oliver (1991) stated some of the possible responses (including avoidance and defiance) and research in other organizational fields has also identified "decoupling"26 as a strategic response (Scott, 1995). When institutional change is perceived within the organization to lead to a conflict of goals, then the likely organizational response will be compromise, if not avoidance (Oliver 1991).

There are other analytical approaches to explain the limited presence of convergence; for example, the time frame could reveal that pressures from the environment and innovations take time to diffuse and be adopted; it may also be the case that after a period of convergence there could be a time of divergence (Kraatz and Zajac 1996). Despite pertaining to the same populations and the same organizational field, technical environmental changes at a global level could exert pressure in the direction of convergence, but divergence can be the result of pressures from the local technical environment (Zajac and Kraatz 1993). Also, managers play a critical role in interpreting the environmental pressures that are subsequently translated into organizational action (George et al 2006).

\footnotetext{
${ }^{26}$ Meyer and Rowan (1977) use the term "decoupling", which consists in adopting a structure for purposes of legitimacy but not implementing it in practice. It is too early to assess whether the development of strategic plans at our government laboratories under study, an action they were legally obligated to undertake, will evolve as an example of decoupling.
} 
Additionally we should note some methodological caveats to our analysis. First, we have monitored a short period of time; additionally, increasing the number of control variables and developing multivariate analysis could also improve the robustness of the analysis. In further research we will explore the relation between funding strategies and other features of the centers, such as age, size, field of research, research outputs, academic rank of permanent and non permanent staff, etc. Microdata on funding and timeframe for project funding would also be useful to assess if there has been increasing funding for longer projects. Second, our qualitative analysis was designed to yield comparable information but rested on interviews from only a few cases. A broad questionnaire-based survey to the centers could provide a larger number of responses.

Acknowledging the general limitations of research based only on two types of research centers, we believe nevertheless that these findings have a number of implications for theory and policy. On the theoretical side, our findings on Spanish research centers are more supportive of frameworks that propose that organizations are active strategic actors that can respond differently to common isomorphic pressures than of frameworks that propose strong "conformity" models. On the policy side, the main implication relates to government laboratories that seem to be less responsive to institutional pressures to conform to new models that imply changes in the internal distribution of authority and power. Incentives for transformation or conformity that are exclusively built on funding instruments might fail to achieve structural change. Regulatory reforms might be necessary to find higher degrees of isomorphism in public sector research. 


\section{REFERENCES}

Ashworth, R., Boyne. G., Delbridge, R. (2009). Escape from the Iron Cage? Organizational Change and Isomorphic Pressures in the Public Sector. Journal of Public Administration Research and Theory, 19(1), 165-187.

Barbacid M. (2008). Interview in "Focus on Europe: Research by the Numbers? by Jill U. Adams AAAS/Science, 11 July 2008, 269-273.

Boden R., Cox, D., Nedeva, M. (2006). The appliance of Science?-New Public Management and Strategic Change. Technology Analysis and Strategic Management, 18(2), 125-241.

Boden, R., Cox, D., Nedeva, M., \& Barker, K. (2004). Scrutinising Science: The Changing UK Government of Science. Houndmills - New York: Palgrave- Macmillan.

Boxenbaum, E., \& Jonsson, S. (2008). Isomorphism, Diffusion and Decoupling. In R. Greenwood, Ch. Oliver, R., Suddaby, \& K. Sahlin (Eds.), The SAGE Handbook of Organizational Institutionalism (pp.78-98). London: Sage.

Bozeman, B. (1987). All Organizations Are Public: Comparing Public And Private Organizations. Washington, DC: Beard Books (reprint 2004).

Bozeman, B., \& Boardman, P.C. (2003). Managing the New Multipurpose Multidiscipline University Research Centers: Institutional Innovation in the Academic Community. Arlington, VA: IBM Center for the Business of Governments.

Bozeman, B., Boardman, C. (2004). The NSF Engineering Research Centers and the University-Industry Research Revolution: A Brief History Featuring an Interview with Erich Bloch. Journal of Technology Transfer, 29(3-4), 365-375.

Bozeman, B., Crow; M. (1990). The environments of US R\&D laboratories: political and market influences. Policy Sciences, 23(1), 25-56

Cohen, L., Duberley, J., McAuley, J. (1999). The Purposes and Process of Science: Contrasting Understandings in UK Research Institutions. R\&D Management, 29(3), 233-245.

Cox, D., Gummett, P., \& Barker, K. (Eds.) (2001). Government Laboratories. Transition and Transformation. Amsterdam: IOS Press.

Crow, M., Bozeman, B. (1987). R\&D Laboratory classification and Public Policy. The effects of the environmental context in laboratory behavior. Research Policy, 16(5), 229-258.

Crow, M., \& Bozeman, B. (1998). Limited by Design. R\&D Laboratories in the U.S. National Innovation System. New York: Columbia University Press.

Crow, M., Emmert, M.A., Jacobson, C.I. (1990). Government-supported industrial research institutes in the United States. Policy Studies Journal, 19(1), 59-74.

Cruz-Castro, L., Sanz-Menéndez, L. (2007). New legitimation models and the transformation of the research field. International Studies of Management and Organization, 37(1), 27-52.

Deephouse, D. (1996). Does Isomorphism legitimate?. Academy of Management Journal, 30 (4), 1024-1039.

DiMaggio, P.J., Powell, W.W. (1983). The iron cage revisited: Institutional isomorphism and collective rationality in organizational fields. American Sociological Review, 48(2), 147-160.

EUROLABS (2002). A comparative Analysis of Public, semi-public and recently privatised Research Centres, PREST on behalf of a project Consortium (PREST, CSI_EM, SISTER, CSIC_UPC). July 2002. Brussels: CEC. ftp://ftp.cordis.lu/pub/rtd2002/docs/ind_report_prest1.pdf. Accessed 1 August 2008.

Feller, I., Ailes, C.P., Roessner, J.D. (2002). Impacts of research universities on technological innovation in industry: evidence from engineering research centres. Research Policy, 31(3), 457-474.

Fligstein, N. (1991). The structural transformation of American industry: An institutional account of the causes of diversification of the large firms, 1919-1979. In W.W. Powell \& P.J. DiMaggio (Eds.). The New Institutionalism in Organizational Analysis (pp. 311-336). Chicago: Chicago University Press.

Frumkin, P., Galaskiewicz, J. (2004). Institutional Isomorphism and Public Sector Organizations. Journal of Public Administrations Research and Theory, 14(3), 283-307.

George, E., Chattopadhyay, P., Sitkin, S.B., Barden, J. (2006). Cognitive Underpinnings of Institutional Perspectives and change: A framing perspective. Academy of Management Review, 31(2), 347-365.

Gibbons, M., Limoges, C., Nowotny, S., Schwartzman, S., Scott, P. \& Trow, M. (1994). The new production of knowledge. The dynamics of science and research in contemporary societies. London: SAGE Publications. 
Greenwood, R., Oliver, Ch. Suddaby, R., \& Sahlin, K. (Eds.) (2008). Isomorphism, Diffusion and Decoupling. In, The SAGE Handbook of Organizational Institutionalism. London: Sage.

Haveman, H.A. (1993). Follow the leader: Mimeric isomorphism and entry into new markets. Administrative Science Quarterly, 38(4), 593-627.

Heimer, C.A. (1999). Comparing Institutions: Law, Medicine, and Family in Neonatal Intensive Care. Law \& Society Review, 33(1), 17-66.

Jansen, D., (Ed.) (2007). New Forms of Governance in Research Organizations: Disciplinary Approaches, Interfaces and Integration, Dordrecht: Springer.

Jordan, G.B. (2001). Measuring the Performance of American Science and Technology Laboratories. In: D. Cox, P. Gummett \& K. Barker (Eds.), Government Laboratories. Transition and Transformation (pp. 174-186). Amsterdam: IOS Press.

Kraatz, M.S., Zajac, E.J. (1996). Exploring the limits of New Institutionalism: The Causes and Consequences of Illegitimate Organizational Change. American Sociological Review, 61(5), 812-836.

Larédo, P. (2001). Government Laboratories or Public Institutions of Professional research: the case of France. In D. Cox, P. Gummett, \& K. Barker (Eds.). Government Laboratories. Transition and Transformation (pp. 114-127). Amsterdam: IOS Press.

Larédo, P., Mustar, P. (2004). Public sector research: A growing role in innovation systems. Minerva, 42(1), 11-27.

Lin, M.W., Bozeman B. (2006). Researchers' Industry Experience and Productivity in University-Industry Research Centers: A "Scientific and Technical Human Capital” Explanation. Journal of Technology Transfer, 31(2), 269290.

Liyanage, S., Mitchell, H. (1993). Organizational management in Australian cooperative research centres. Technology Analysis and Strategic Management, 5(1), 3-14.

Meyer, J.W., Rowan, B. (1977). Institutionalized organizations: Formal structure as myth and ceremony. American Journal of Sociology, 83(2), 340-363.

Meyer, J.W., Scott, R.W. and Strange D. (1987). Centralization, fragmentation, and school district complexity. Administrative Science Quarterly 32 (2) 186-202.

Mizruchi, M.S., Fein, L.C. (1999). The Social Construction of Organizational Knowledge: A Study of the Uses of Coercitive, Mimetic, and Normative Isomorphism. Administrative Science Quarterly, 44(4), 653-683.

Moso, M., Olazaran, M. (2002). Regional technology policy and the emergence of an R\&D system in the Basque country. Journal of Technology Transfer, 27(1), 61-75.

Nedeva, M., Boden, R (2006). Changing Science: The Advent of Neo-liberalism. Prometheus, 24(3), $269-281$.

Nowotny, H., Scott, P., \& Gibbons, M. (2001). Re-Thinking Science. Knowledge and the Public in an Age of Uncertainty. Cambridge: Polity.

OECD (1989). The changing role of Government Research Laboratories. Paris: OECD.

OECD (2003). Governance of Public research. Toward better practices. Paris: OECD.

OECD (2004). OECD Science, technology and Industry Outlook 2004. Paris: OECD

OECD (2009). Main Science and Technology Indicators 2009/1. Paris: OECD.

Oliver, C. (1991). Strategic responses to institutional process. Academy of Management Review, 16(1), 145-179.

Perry, J.L., Rainey, H.G. (1988). The Public-Private Distinctions in Organization Theory. Academy of Management Review, 13(2), 182-201.

Pestre, D. (2003). Regimes of Knowledge Production in Society: Towards a more Political and Social Reading. Minerva, 41(3), 245-261.

Rainey, H.G., Bozeman, B. (2000). Comparing Public and Private Organizations. Empirical research and the Power of A Priori. Journal of Public Administration Research and Theory, 10(2), 447-469.

Rip, A. (2002). Regional Innovation Systems and the Advent of Strategic Science. Journal of Technology Transfer, 27(1), 123-231.

Ruef, M., Scott, W.R. (1998). A Multidimensional Model of Organizational Legitimacy: Hospital Survival in Changing Institutional Environments. Administrative Science Quarterly, 43(4), 877-904. 
Sanz-Menéndez, L., Cruz-Castro, L. (2003). Coping with environmental pressures: Public Research Organizations responses to funding crisis. Research Policy, 32 (8), 1293-1308.

Sanz-Menéndez, L.; Cruz-Castro, L. (2005). Explaining the science and technology policies of regional governments. Regional Studies, 39(7), 939-954.

Sanz G., Fuster, V. ( 2008). Spanish National Center for Cardiovascular Research (CNIC): pioneering a new model for funding biomedical research. Nature Clinical Practice. Cadiovascular Medicine, CNIC Edition, 5(11), 19-23.

Schimank, U. \& Stucke, A. (1994). Coping with Trouble as a Complex Constellation of Political and Research Actors: Introducing a Theoretical Perspective. In U. Schimank, \& A. Stucke (Eds). Coping with Trouble. How Science reacts to Political Disturbances of Research Conditions (pp. 7-34). Frankfurt-New York: Campus VerlagSt.Martin's Press.

Scott, W.R. (1987). The adolescence of institutional theory. Administrative Science Quarterly, 32(4). $493-511$.

Scott, W.R. (1995). Institutions and organizations. Thousand Oaks, CA: Sage.

Scott, W.R. (2008). Approaching adulthood: the maturing of institutional theory. Theory and Society, 37 (5), $427-442$.

Senker, J. (2000). Introduction to a special issue on changing organization and structure of European public-sector research systems. Science and Public Policy, 27(6), 394-396.

Smith, J. (2000). From R\&D to strategic Knowledge management: transitions and challenges for national laboratories. $R \& D$ Management, 30(4), 305-311.

Stokes, D.E. (1997). Pasteurs Quadrant: Basic Science and Technological Innovation. Washington, DC: The Brooking Institution.

Van der Meulen, B.J.R., \& Rip, A. (1994). Research Institutes in Transition. Enschede: University of Twente -WMW.

Weingart, P. (1997). From "Finalization" to "Mode 2": old wine in new bottles?. Social Science Information, 36(4), 591-613.

Zajac, E.J., Kraatz, M.S. (1993). A Diametric Forces Model of Strategic Change: Assessing the Antecedents and Consequences of Restructuring in the Higher Education Industry. Strategic Management Journal, 14 (special issue: Corporate Restructuring), 83-102. 


\section{ANNEX}

Table A1. Descriptive statistic for funding shares by source

\begin{tabular}{|c|c|c|c|c|c|c|c|c|c|c|c|c|}
\hline & & Tecl & $\begin{array}{l}\text { ology ce } \\
(N=54)\end{array}$ & & & & Gove & $\begin{array}{l}\text { ent lab } \\
(\mathrm{N}=81)\end{array}$ & ories & & $\begin{array}{r}\text { T-test fo } \\
m\end{array}$ & $\begin{array}{l}\text { uality of } \\
s^{*}\end{array}$ \\
\hline & Mean & Median & Min & Max & $\begin{array}{l}\text { Std. } \\
\text { Desv. }\end{array}$ & Mean & Median & Min & Max & $\begin{array}{l}\text { Std. } \\
\text { Desv. }\end{array}$ & $t$ & $\begin{array}{c}\text { Sig. } \\
\text { (2 tailed) }\end{array}$ \\
\hline Public non competitive 2002 & 0.13 & 0.13 & 0.00 & 0.54 & 0.14 & 0.74 & 0.76 & 0.21 & 0.99 & 0.15 & -24.35 & 0.000 \\
\hline Public non competitive 2003 & 0.11 & 0.06 & 0.00 & 0.46 & 0.13 & 0.73 & 0.76 & 0.16 & 0.99 & 0.13 & -26.92 & 0.000 \\
\hline Public non competitive 2004 & 0.12 & 0.08 & 0.00 & 0.56 & 0.13 & 0.69 & 0.71 & 0.25 & 0.90 & 0.11 & -26.19 & 0.000 \\
\hline Public non competitive 2005 & 0.09 & 0.03 & 0.00 & 0.39 & 0.11 & 0.69 & 0.70 & 0.30 & 0.91 & 0.11 & -31.66 & 0.000 \\
\hline Public non competitive 2006 & 0.09 & 0.08 & 0.00 & 0.41 & 0.10 & 0.71 & 0.71 & 0.40 & 0.92 & 0.10 & -34.94 & 0.000 \\
\hline Public non competitive 2007 & 0.08 & 0.07 & 0.00 & 0.37 & 0.10 & 0.72 & 0.73 & 0.43 & 0.92 & 0.09 & -38.12 & 0.000 \\
\hline Public competitive 2002 & 0.29 & 0.27 & 0.00 & 1.00 & 0.18 & 0.22 & 0.19 & 0.00 & 0.79 & 0.14 & 2.34 & 0.021 \\
\hline Public competitive 2003 & 0.29 & 0.29 & 0.00 & 0.60 & 0.16 & 0.22 & 0.19 & 0.01 & 0.84 & 0.12 & 3.00 & 0.003 \\
\hline Public competitive 2004 & 0.30 & 0.32 & 0.00 & 0.52 & 0.15 & 0.26 & 0.24 & 0.06 & 0.75 & 0.12 & 1.52 & 0.132 \\
\hline Public competitive 2005 & 0.34 & 0.34 & 0.00 & 0.70 & 0.16 & 0.26 & 0.25 & 0.08 & 0.68 & 0.11 & 3.21 & 0.002 \\
\hline Public competitive 2006 & 0.35 & 0.36 & 0.00 & 0.67 & 0.15 & 0.22 & 0.22 & 0.04 & 0.47 & 0.09 & 5.63 & 0.000 \\
\hline Public competitive 2007 & 0.35 & 0.35 & 0.00 & 0.68 & 0.17 & 0.24 & 0.23 & 0.08 & 0.48 & 0.09 & 4.54 & 0.000 \\
\hline Market 2002 & 0.58 & 0.59 & 0.00 & 0.97 & 0.18 & 0.04 & 0.03 & 0.00 & 0.29 & 0.06 & 21.20 & 0.000 \\
\hline Market 2003 & 0.60 & 0.59 & 0.21 & 0.94 & 0.15 & 0.05 & 0.04 & 0.00 & 0.30 & 0.06 & 25.81 & 0.000 \\
\hline Market 2004 & 0.59 & 0.57 & 0.26 & 0.89 & 0.13 & 0.05 & 0.04 & 0.00 & 0.27 & 0.06 & 27.69 & 0.000 \\
\hline Market 2005 & 0.57 & 0.55 & 0.30 & 0.99 & 0.15 & 0.05 & 0.04 & 0.00 & 0.32 & 0.06 & 25.01 & 0.000 \\
\hline Market 2006 & 0.56 & 0.56 & 0.33 & 0.87 & 0.13 & 0.06 & 0.05 & 0.00 & 0.29 & 0.06 & 26.95 & 0.000 \\
\hline Market 2007 & 0.57 & 0.55 & 0.32 & 0.99 & 0.14 & 0.04 & 0.03 & 0.00 & 0.26 & 0.04 & 27.04 & 0.000 \\
\hline Avg. public non competitive 2002-2003 & 0.12 & 0.10 & 0.00 & 0.46 & 0.12 & 0.73 & 0.75 & 0.19 & 0.99 & 0.13 & -27.56 & 0.000 \\
\hline Avg. public non competitive 2006-2007 & 0.09 & 0.07 & 0.00 & 0.39 & 0.10 & 0.72 & 0.73 & 0.41 & 0.92 & 0.09 & -38.21 & 0.000 \\
\hline Avg. public competitive 2002-2003 & 0.29 & 0.30 & 0.00 & 0.60 & 0.15 & 0.22 & 0.20 & 0.01 & 0.81 & 0.12 & 3.01 & 0.003 \\
\hline Avg. public competitive 2006-2007 & 0.35 & 0.36 & 0.00 & 0.60 & 0.15 & 0.23 & 0.23 & 0.06 & 0.47 & 0.08 & 5.45 & 0.000 \\
\hline Avg. market 2002-2003 & 0.59 & 0.59 & 0.18 & 0.94 & 0.15 & 0.05 & 0.03 & 0.00 & 0.27 & 0.05 & 24.82 & 0.000 \\
\hline Avg. market 2006-2007 & 0.56 & 0.56 & 0.38 & 0.93 & 0.12 & 0.05 & 0.04 & 0.00 & 0.27 & 0.05 & 29.50 & 0.000 \\
\hline
\end{tabular}

* Equal variances not assumed

Table A2. Clusters of changes in funding shares by source*

Differences between average funding share in 2006/07 and average funding share in 2002/03

\begin{tabular}{|c|c|c|c|c|c|c|c|c|c|c|}
\hline & \multicolumn{5}{|c|}{$\begin{array}{l}\text { Technology centers } \\
\quad(\mathrm{N}=54)\end{array}$} & \multicolumn{5}{|c|}{$\begin{array}{l}\text { Government laboratories } \\
\qquad(\mathrm{N}=81)\end{array}$} \\
\hline & \multicolumn{3}{|c|}{$\begin{array}{c}\text { Final cluster centers } \\
\text { (number of cases in each cluster) } \\
\end{array}$} & \multicolumn{2}{|c|}{ ANOVA $A^{\star *}$} & \multicolumn{3}{|c|}{$\begin{array}{c}\text { Final cluster centers } \\
\text { (number of cases in each cluster) } \\
\end{array}$} & \multicolumn{2}{|c|}{ ANOVA $^{\star \star}$} \\
\hline & Cluster 1 & Cluster 2 & Cluster 3 & $\mathrm{~F}$ & Sig. & Cluster 1 & Cluster 2 & Cluster 3 & $\mathrm{~F}$ & Sig. \\
\hline Public non competitive & $\begin{array}{c}-0.0078 \\
(33)\end{array}$ & $\begin{array}{c}-0.1797 \\
(13)\end{array}$ & $\begin{array}{c}0.1066 \\
(8)\end{array}$ & 84.115 & .000 & $\begin{array}{c}0.4575 \\
(2)\end{array}$ & $\begin{array}{c}0.0616 \\
(25)\end{array}$ & $\begin{array}{c}-0.0710 \\
(54)\end{array}$ & 117.556 & .000 \\
\hline Public competitive & $\begin{array}{c}0.2742 \\
(11)\end{array}$ & $\begin{array}{c}0.0475 \\
(32)\end{array}$ & $\begin{array}{c}-0.1213 \\
(11)\end{array}$ & 110.358 & .000 & $\begin{array}{c}-0.5430 \\
(1)\end{array}$ & $\begin{array}{c}0.0581 \\
(58)\end{array}$ & $\begin{array}{c}-0.0858 \\
(22)\end{array}$ & 92.628 & .000 \\
\hline Market & $\begin{array}{c}-0.1863 \\
(12)\end{array}$ & $\begin{array}{c}-0.0170 \\
(33)\end{array}$ & $\begin{array}{l}0.1485 \\
(9)\end{array}$ & 91.527 & .000 & $\begin{array}{c}-0.1111 \\
(4)\end{array}$ & $\begin{array}{c}0.0027 \\
(62)\end{array}$ & $\begin{array}{c}0.0479 \\
(15)\end{array}$ & 152.805 & .000 \\
\hline
\end{tabular}

* K-means clusters

** The F tests should be used only for descriptive purposes because the clusters have been chosen to maximize the differences among cases in different clusters. The observed significance levels are not corrected for this and thus cannot be interpreted as tests of the hypothesis that the cluster means are equal. 
Table 1. Stylized features of government and technology centers v. hybrid centers

\begin{tabular}{|l|l|l|l|}
\hline & \multicolumn{1}{|c|}{ Hybrid centers } & Government laboratories & \multicolumn{1}{|c|}{ Technology centers } \\
\hline $\begin{array}{l}\text { Legal status } \\
\text { governance }\end{array}$ & $\begin{array}{l}\text { Independent private nonprofit } \\
\text { foundation with representation of } \\
\text { public and private actors usually } \\
\text { included in the Governing Board. In } \\
\text { some cases also an Industrial Advisory } \\
\text { Board. }\end{array}$ & $\begin{array}{l}\text { Public centers belonging to the } \\
\text { Consejo Superior de } \\
\text { Investigaciones Científicas } \\
\text { (CSIC). No independent legal } \\
\text { status from CSIC }\end{array}$ & $\begin{array}{l}\text { Private nonprofit organization, most } \\
\text { of them affiliated to the Spanish } \\
\text { Federation of Technology Centers } \\
\text { (FEDIT). }\end{array}$ \\
\hline Missions & $\begin{array}{l}\text { To produce research and advance } \\
\text { knowledge on socially and } \\
\text { economically relevant problems, } \\
\text { working in a problem solving mode, } \\
\text { valorizing research results. }\end{array}$ & $\begin{array}{l}\text { To conduct fundamental and } \\
\text { applied research. }\end{array}$ & $\begin{array}{l}\text { To support innovation and improve } \\
\text { competitiveness of firms, mainly } \\
\text { SMEs through the provision of R\&D } \\
\text { and services on demand. }\end{array}$ \\
\hline $\begin{array}{l}\text { Funding } \\
\text { bat usually block grant support of } \\
\text { public actors involved in their creation } \\
\text { (normally in the context of "Strategic } \\
\text { Plans") and search for external funds } \\
\text { (either competitive public or private) } \\
\text { for carrying out research projects } \\
\text { defined in the strategic choices. }\end{array}$ & $\begin{array}{l}\text { Mix of funding sources, mainly } \\
\text { public, with a significant role of } \\
\text { direct transfers from government }\end{array}$ & $\begin{array}{l}\text { Mix of funding sources, mainly } \\
\text { private, obtained both from research } \\
\text { contracts and services provided to } \\
\text { industry. }\end{array}$ \\
\hline $\begin{array}{l}\text { Human } \\
\text { resources } \\
\text { management }\end{array}$ & $\begin{array}{l}\text { Private law (not civil service model). } \\
\text { External and international recruitment } \\
\text { in a world research market. Conditions } \\
\text { based on reputation and performance. }\end{array}$ & $\begin{array}{l}\text { Civil service model. Lack of } \\
\text { capability to negotiate individual } \\
\text { salaries and rewards. } \\
\text { Performances playing a minor } \\
\text { role differentiating earnings. }\end{array}$ & $\begin{array}{l}\text { Private law, competitive salaries for } \\
\text { regional business market. Rewards } \\
\text { based on fulfillment of objectives. }\end{array}$ \\
\hline
\end{tabular}

Source: Own elaboration based on Annual Reports and funding data from CSIC, FEDIT, CERCA, CNIO and CNIC. 
Figure 1. Classification scheme for research centers

\begin{tabular}{|c|c|c|c|c|}
\hline \multirow{3}{*}{ 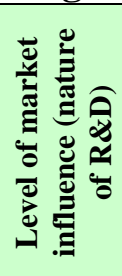 } & $\begin{array}{l}\text { Proprietary product } \\
\text { (high) }\end{array}$ & & Mixed-source technology & Public technology \\
\hline & $\begin{array}{l}\text { Balanced product } \\
\text { (moderate) }\end{array}$ & $\begin{array}{c}\text { Private science and } \\
\text { technology }\end{array}$ & $\begin{array}{l}\text { Mixed-source science and } \\
\text { technolog }\end{array}$ & $\begin{array}{l}\text { Public science and } \\
\text { technology }\end{array}$ \\
\hline & $\begin{array}{l}\text { Generic product } \\
\text { (low) }\end{array}$ & Private niche science & Mixed-source science & Public science \\
\hline & & Low & Moderate & High \\
\hline
\end{tabular}

Source: Elaboration based on Bozeman (1987), Bozeman and Crow (1990), Crow, Emmert and Jacobson (1990), Crow and Bozeman (1987) with transposition of Y values. 
Figure 2. Distribution of research centers by funding shares: 2002-2003 / 2006-2007

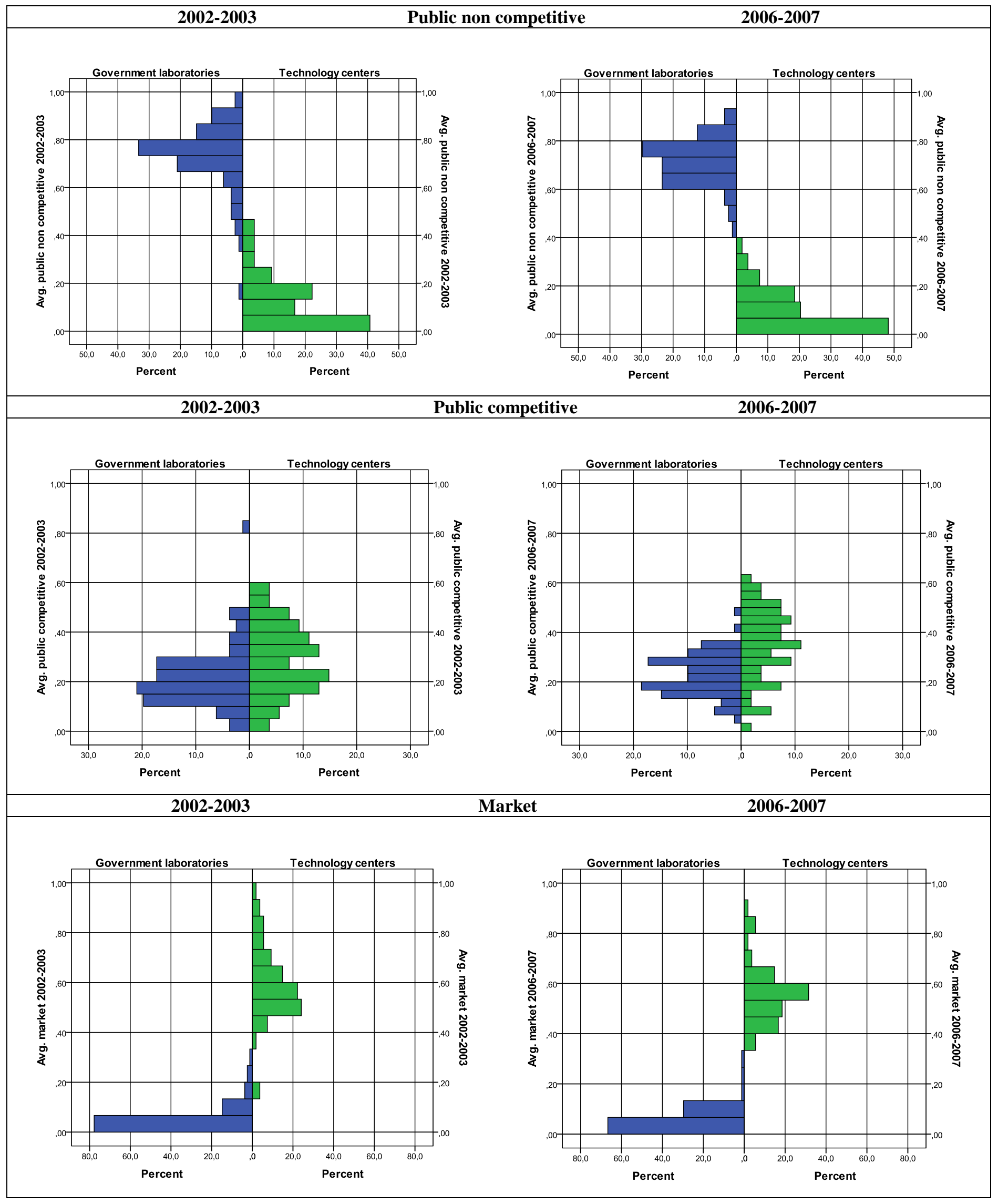


Figure 3. Distribution of research centers by funding strategy

Based on clusters of changes in average funding shares for each population between 2002-2003 and 2006-2007

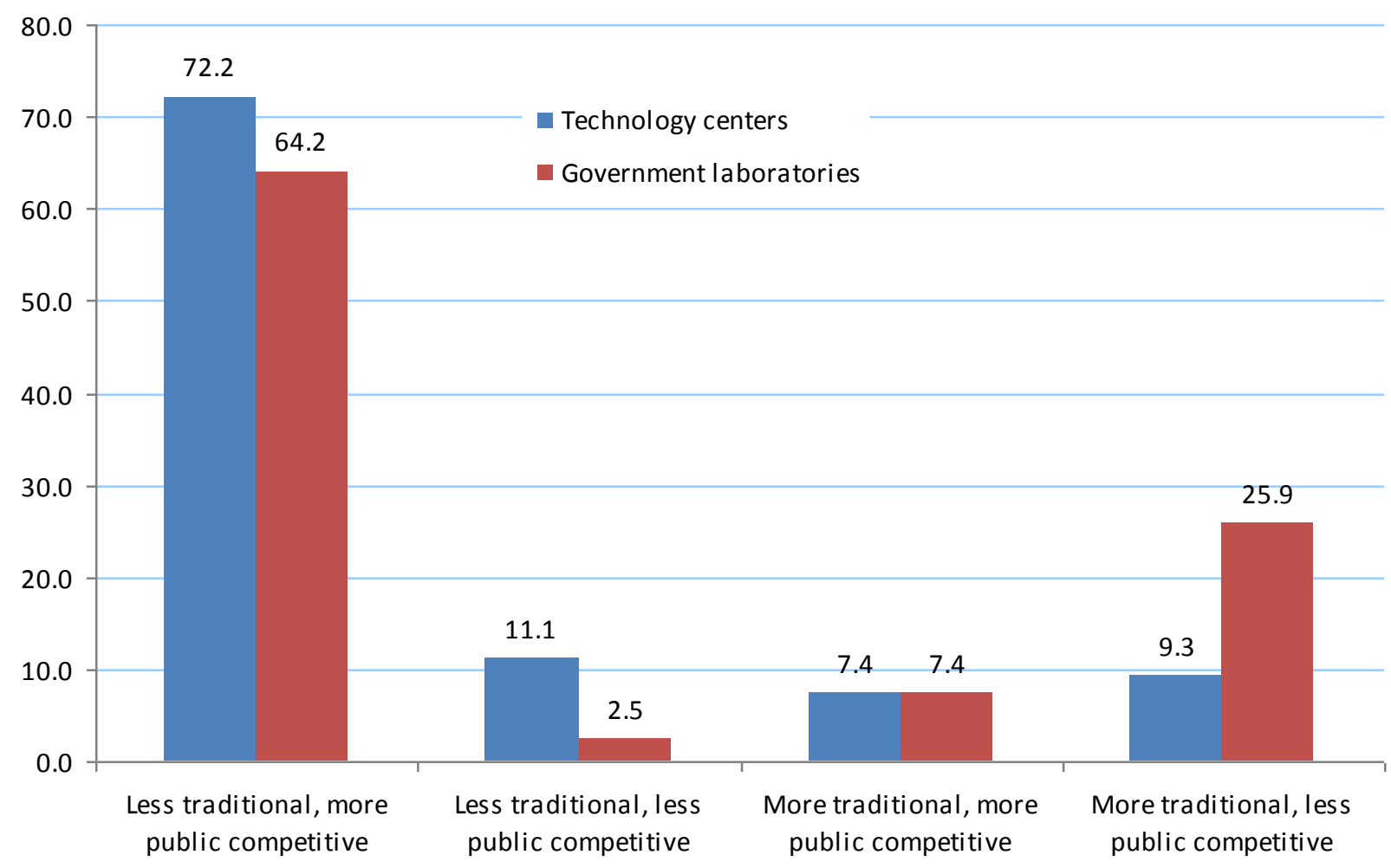


Table 2. Summary of research planning and agenda setting features at government and technology centers $v$. hybrid centers

\begin{tabular}{|l|l|l|l|}
\hline & Level of agenda setting & Research planning & Changes over time \\
\hline Hybrid centers & $\begin{array}{l}\text { Organizational: scientific } \\
\text { directorship plus advisory } \\
\text { boards }\end{array}$ & $\begin{array}{l}\text { Multiannual } \\
\text { Program basis }\end{array}$ & Stable \\
\hline Technology centers & $\begin{array}{l}\text { Top Management plus } \\
\text { consultation with head of } \\
\text { departments. } \\
\text { Increasingly organizational }\end{array}$ & $\begin{array}{l}2 \text { tracks } \\
1^{\text {st }} \text {-project basis with the } \\
\text { contracting firms } \\
2^{\text {nd }} \text { - Multiannual generic } \\
\text { technology development } \\
\text { programs }\end{array}$ & $\begin{array}{l}\text { Establishment of the second } \\
\text { track from the mid nineties } \\
\text { and plans to reduce the } \\
\text { share of the first one }\end{array}$ \\
\hline $\begin{array}{l}\text { Government } \\
\text { laboratories }\end{array}$ & $\begin{array}{l}\text { Micro level: Research } \\
\text { groups and individual } \\
\text { researchers }\end{array}$ & $\begin{array}{l}\text { Follows competitive national } \\
\text { calls cycle } \\
\text { Project basis (usually short- } \\
\text { term) }\end{array}$ & $\begin{array}{l}\text { Strategic plans (four years) } \\
\text { started recently }\end{array}$ \\
\hline
\end{tabular}

Source: Own elaboration based on interviews 